\title{
Development of a grapevine detached root assay for assessing pathogenicity of Cylindrocarpon spp.
}

\author{
B. Pathrose, E.E. Jones, M.V. Jaspers and H.J. Ridgway \\ Faculty of Agriculture and Life Sciences, Lincoln University, Lincoln, New Zealand \\ Corresponding author:Blessy.Pathrose@lincolnuni.ac.nz
}

\begin{abstract}
An in vitro method was developed to determine the relative pathogenicity of C. macrodidymum, C. liriodendri and C. destructans isolates on grapevine roots. Young feeder roots of similar age and diameter were placed individually into Petri dishes containing water-saturated silica sand, with the basal cut ends of the roots inserted into tubes filled with sterile water. Three isolates each of $C$. macrodidymum and C. liriodendri and two of C. destructans were inoculated as mycelial plugs onto the wounded roots, three replicates per isolate. After 1 month, all inoculated roots had dark brown lesions (range of lengths $28.7-40.4 \mathrm{~mm}$ ) that were significantly different between isolates, with an isolate of C. liriodendri having the longest lesions and an isolate of $C$. destructans the shortest. This assay provides a rapid in vitro method to screen large numbers of Cylindrocarpon spp. isolates.
\end{abstract}

Keywords Cylindrocarpon species, detached root assay, lesion length, pathogenicity.

\section{INTRODUCTION}

Black foot disease of grape, caused by Cylindrocarpon species, is a problem in vineyard establishment worldwide. Over the last decade, its incidence has increased significantly in all major viticulture regions throughout the world, including South Africa, New Zealand, Italy, Australia and North America (Halleen et al. 2004a; Petit \& Gubler 2005; Alaniz et al. 2009). Although the disease occurs in young and mature vines, losses usually occur during the first 5 years, sometimes even during the first year after planting (Halleen et al. 2006).

The symptoms include delayed or absence of budding, slow growth, reduced vigour, shortened internodes, sparse and chlorotic foliage with necrotic margins, wilting and dieback, as well as necrotic root crowns and development of secondary root systems. Grapevine roots affected by black foot disease show sunken necrotic lesions with a reduction in biomass. The below ground rootstock trunk develops black discoloration and necrosis of wood tissues (Halleen et al. 2004b; Alaniz et al. 2009).

In New Zealand Cylindrocarpon macrodidymum, C. destructans and C. liriodendri are pathogenic to grapevines, although their isolates vary in pathogenicity. Research by Alaniz et al. (2009) showed that specific isolate genotypes could be linked to virulence but the link between genotypic diversity and virulence has not been studied for New Zealand isolates. This research aimed to develop a detached root 
assay to provide a rapid in vitro method that could screen a large number of isolates for their relative pathogenicity to grapevine roots.

\section{MATERIALS AND METHODS \\ Fungal isolates}

Three isolates each of C. macrodidymum $(\mathrm{C06a}=$ ICMP 16788, Hb4a and Nel1b) and C. liriodendri (Co5c, Hb5a and Hb2d = ICMP 16790) and two of C. destructans (Mar11e and Mar15a), previously identified using morphological and molecular methods, were grown on potatodextrose agar (PDA; Oxoid) for 7 days at $20^{\circ} \mathrm{C}$ with 12:12 h dark:light.

\section{Selection of roots}

As the physical characteristics of grapevine roots vary significantly, care was taken to collect roots of similar diameter and pigmentation. The younger outer feeder roots were removed from potted 1-year-old Vitis riparia $\times$ V. rupestris cv. 101-14 rootstock plants and washed in tap water to remove the soil. The roots of rootstock 101-14 were used as this variety had previously been shown to be susceptible to Cylindrocarpon infection.

\section{Detached root assay}

The three replicate roots per Cylindrocarpon isolate were placed individually into Petri dishes $(90 \times 15 \mathrm{~mm})$ containing $30 \mathrm{~g}$ of silica sand wetted with $9 \mathrm{ml}$ of sterile water. The basal cut end of each root was inserted through a Parafilm ${ }^{\mathrm{TM}}$ cap into a $1.7 \mathrm{ml}$ tube filled with sterile water to keep the root hydrated during the experiment. The apical end of each root was cut across and a mycelial plug taken from the growing edge of a fungal colony placed against the cut end. The experiment was duplicated using mycelial plugs grown on either half or full strength PDA. Control roots had plugs of half or full strength PDA placed against the cut ends. The Petri dishes were sealed with clingfilm, incubated at room temperature and after 1 month, the lesion lengths were measured using a digital calliper (Mitutoyo, U.K Ltd).

To reisolate the pathogen, the roots were surface sterilised for $3 \mathrm{~min}$ in $0.35 \%$ sodium hypochlorite and washed in sterile water twice for $2 \mathrm{~min}$. Each root was sequentially cut $(1 \mathrm{~cm}$ lengths) and the pieces from both the lesions and the apparently healthy root sections were placed onto PDA amended with chloramphenicol (250 $\mathrm{mg} /$ litre). The plates were incubated at $20^{\circ} \mathrm{C}$ in $12: 12 \mathrm{~h}$ light:dark for 7 days. Colony and conidium morphology was used to identify the Cylindrocarpon spp.

The lesion length data were analysed by ANOVA using GenStat version 12.

\section{RESULTS}

All inoculated roots (Figure 1b) had dark brown lesions that were clearly distinguishable from the remaining healthy root. Control roots (Figure 1a) had only minor discolourations at the apical cut ends after 1 month incubation.
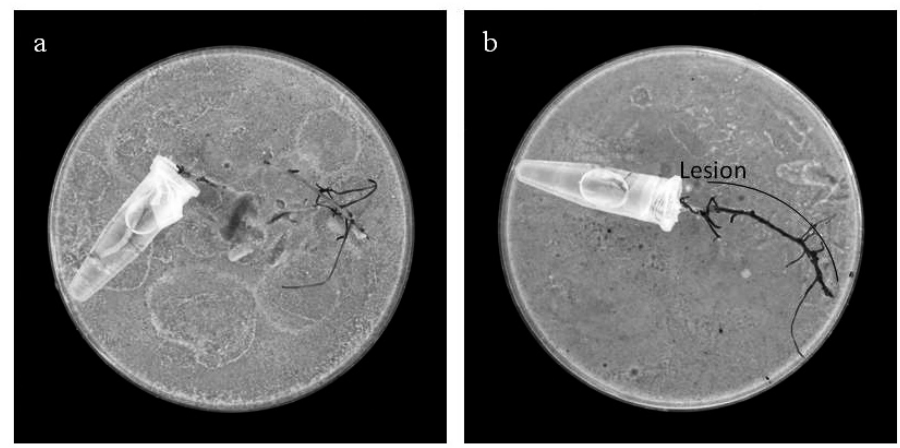

Figure 1 Experimental set-up for the detached root assay, shown 1 month after inoculation. (a) Control root showing healthy root material and (b) root inoculated with C. liriodendri isolate Co5c showing development of the black lesion from the apical end. 
The lesion length differed $(\mathrm{P}<0.05)$ between isolates (Table 1). The largest lesions were produced on $1 / 2 \mathrm{PDA}$ by $C$. liriodendri isolate $\mathrm{C} 05 \mathrm{c}$ $(40.4 \mathrm{~mm})$ and on PDA by C. liriodendri isolate $\mathrm{Hb} 5 \mathrm{a}$ and C. destructans isolate Mar11e (38.9 and $39.3 \mathrm{~mm}$, respectively). The smallest lesions were produced by $C$. destructans isolates Mar11e and Mar15a on $1 / 2$ PDA and PDA (28.7 and $30.0 \mathrm{~mm}$, respectively).

There was a significant interaction between agar type and isolate $(\mathrm{P}<0.001)$ (Table 1$)$. Several isolates (Co5c, Nel1b and Mar15a) that produced large lesions when inoculated as colonised $1 / 2 \mathrm{PDA}$ plugs produced significantly smaller lesions when inoculated as colonised PDA plugs. For isolates $\mathrm{Hb} 4 \mathrm{a}$ and Mar11e the reverse was true

Table 1 Lengths (mm) of lesions produced on detached roots of rootstock 101-14 1 month after inoculation with PDA or half strength (1/2) PDA plugs colonised with isolates of $C$. liriodendri, C. macrodydimum or C. destructans.

\begin{tabular}{lccc}
\hline & & \multicolumn{2}{c}{ Lesion length $(\mathrm{mm})^{1}$} \\
\cline { 3 - 4 } Species & Isolate & $1 / 2$ PDA & PDA \\
\hline C. liriodendri & & \\
& Co5c & $40.4 \mathrm{a}$ & $34.6 \mathrm{~b}$ \\
& Hb5a & $32.4 \mathrm{~cd}$ & $39.3 \mathrm{a}$ \\
Hb2d & $34.9 \mathrm{bc}$ & $34.8 \mathrm{~b}$ \\
C. macrodidymum & & \\
& Co6a & $35.0 \mathrm{c}$ & $34.3 \mathrm{~b}$ \\
& Hb4a & $29.8 \mathrm{de}$ & $37.1 \mathrm{ab}$ \\
& Nel1b & $37.4 \mathrm{ab}$ & $35.0 \mathrm{~b}$
\end{tabular}

C. destructans

$\begin{array}{lll}\text { Mar11e* } & 28.7 \mathrm{e} & 38.9 \mathrm{a} \\ \text { Mar15a* }^{*} & 37.5 \mathrm{ab} & 30.0 \mathrm{c}\end{array}$

Control

$12.2 \mathrm{f} \quad 10.0 \mathrm{~d}$

LSD

$3.44 \quad 3.38$

${ }^{1}$ Means followed by the same letters within each column are not significantly different according to Fishers LSD $\mathrm{P}<0.05$ test. The symbol ${ }^{\star}$ denotes isolates whose lesion lengths differ significantly $(\mathrm{P}<0.05)$ between agar types. with larger lesions produced when the inoculum was in PDA rather than 1/2PDA. Notably, C. destructans isolate Marlle produced the smallest lesion when inoculated as $1 / 2 \mathrm{PDA}$ and the largest lesion when inoculated on PDA.

\section{DISCUSSION}

The in vitro method developed here was able to show varied levels of pathogenicity between the isolates of C. macrodidymum, C. liriodendri and $C$. destructans isolates on grapevine roots, which was supported by earlier studies using potted rootstock plants (Probst et al. 2007). The inoculated roots showed the typical Cylindrocarpon species infection of black discolouration within 1 month. This was faster than disease development in the trunk bases of inoculated vines, which usually takes 3-6 months (Petit \& Gubler 2005; Halleen et al. 2006). This may have been due to the young soft roots selected for the bioassay, the absence of plant defence responses, as the roots were detached from plants, or the absence of competing microbial flora. In addition to the advantage provided by the rapid symptom development, this assay can also be done at any time during the year unlike potted vine trials, which are more seasonally restricted. The potential for greater replication and tighter control over light, temperature and humidity also means that this type of assay has less variability than in potted vine, glasshouse experiments or field trials. In such whole-vine experiments, the variability of the growing season greatly affects results, for example, high temperatures during summer play an important role in symptom expression (Halleen et al. 2006).

This study also showed that the pathogenicity of any isolate's mycelium inoculum was significantly affected by its growing medium. Isolates that were highly pathogenic applied in $1 / 2$ PDA were less pathogenic in PDA and vice versa. While this was surprising, it may reflect differences in the saprophytic ability of the individual isolates. For example, those that were highly pathogenic when applied in $1 / 2$ PDA may have been better able to colonise and access the plant nutrients than other more saprophytic isolates and thus 
were less reliant on the agar medium. In full strength PDA, isolates with greater saprophytic ability can produce a larger biomass and thus be more pathogenic by virtue of inoculum density. Overall the $1 / 2 \mathrm{PDA}$ treatment gave the broader range of pathogenicity (28.7-40.4 mm lesions) compared to the PDA treatment $(30.0-39.3 \mathrm{~mm}$ lesions). To better reflect the natural processes of infection in soil, the assay could be modified to use chlamydospores, which may be produced in liquid culture (Yoo et al. 1996).

Future work will use 200 selected isolates to investigate the relationships between genotypic characters with the pathogenicity of isolates on potted vines and on detached roots. Although there are few reports of detached root assays, use of detached leaf assays have been reported frequently for investigations into fungicide efficacy, induced resistance assays and isolate variation in pathogenicity. They are generally acknowledged to provide a quick and economic method that correlates well with similar assays on whole plants.

\section{ACKNOWLEDGMENTS}

The authors wish to thank New Zealand Winegrowers Inc. for funding this project and Lincoln University for providing a Doctoral Scholarship.

\section{REFERENCES}

Alaniz S, Armengol J, León M, García-Jiménez J, Abad-Campos P 2009. Analysis of genetic and virulence diversity of Cylindrocarpon liriodendri and C. macrodidymum associated with black foot disease of grapevine. Mycological Research 113(1): 16-23.
Halleen F, Schroers HJ, Groenewald JZ, Crous PW 2004a. Novel species of Cylindrocarpon (Neonectria) and Campylocarpon gen. nov. associated with black foot disease of grapevines (Vitis spp.). Studies in Mycology 50: 431-455.

Halleen F, Crous PW, Groenewald JZ 2004b. ITS phylogeny of Cylindrocarpon spp. causal agent of Black Foot Disease of grapevine. Phytopathologia Mediterranea 43: 146-147.

Halleen F, Schroers HJ, Groenewald JZ, Rego C, Oliveira H, Crous PW 2006. Neonectria liriodendri sp. nov., the main causal agent of black foot disease of grapevines. Studies in Mycology 55(1): 227.

Petit E, Gubler WD 2005. Characterization of Cylindrocarpon species, the cause of black foot disease of grapevine in California. Plant Disease 89(10): 1051-1059.

Probst CM, Jones EE, Ridgway HJ, Jaspers MV 2007. Pathogenicity of the different Cylindrocarpon species on grapevines in New Zealand. Proceedings of the $16^{\text {th }}$ Biennial Australasian Plant Pathology Society Conference, Adelaide, Australia, 24-27 September 2007. p. 33 (Abstract).

Yoo S, Cho J, Jo J, Yu S 1996. Effect of physical and chemical factors on the formation and germination of chlamydospores of Cylindrocarpon destructans causing root rot of Panax ginseng. Korean Journal of Plant Pathology 12(4): 422-427. 